\title{
Carcinoma de células de Merkel de región glútea. Reporte de un caso
}

Jimena Garmendia*, Daniel González González†

\section{Resumen}

Introducción: el carcinoma de células de Merkel es un tumor primario maligno de piel que afecta fundamentalmente regiones expuestas a las radiaciones solares. Pocos casos han sido comunicados en una región no expuesta al factor de riesgo mencionado, como es la glútea. El objetivo de este trabajo es comunicar un caso clínico de carcinoma de células de Merkel de región glútea.

Caso clínico: paciente de 63 años, sexo masculino, que consultó por tumoración de $2 \mathrm{~cm}$ de diámetro en región glútea derecha, de rápido crecimiento, que se operó de coordinación con anestesia, realizándose su resección completa. El resultado del estudio anatomopatológico informó carcinoma de células de Merkel.

No se evidenció diseminación a distancia, por lo que de acuerdo con la clasificación TNM se determinó como estadio I. Se completó el tratamiento con radioterapia local. Actualmente el paciente sigue en seguimiento y asintomático.

Discusión: los carcinomas de células de Merkel son tumores altamente agresivos. Además de la radiación solar como factor de riesgo, se mencionan la inmunodeficiencia y un nuevo poliomavirus, el poliomavirus de células de Merkel. Se presentan como tumoraciones de color violáceo y rápido crecimiento, y es frecuente el compromiso ganglionar sincrónico o metacrónico. La resección quirúrgica con márgenes suficientes y vaciamiento ganglionar, en caso de haber compromiso 0 estudio de ganglio centinela en caso de no haberlo, es lo indicado. El pronóstico depende del estadio y se ha reportado hasta $30 \%$ de recidiva a dos años.

Palabras clave: Carcinoma de células de Merkel Nalgas

Key words: $\quad$ Carcinoma, Merkel cell Buttocks

\footnotetext{
* Residente de Cirugía General.

† Profesor titular de Clínica Quirúrgica 3.

Clínica Quirúrgica 3. Facultad de Medicina. Universidad de la República. Hospital Maciel. Montevideo, Uruguay.

Correspondencia: Jimena Garmendia. Asamblea 4339. Montevideo, Uruguay. Correo electrónico: jime2703@hotmail.com

Los autores declaran no tener conflicto de intereses.

Cuenta con consentimiento del paciente para la publicación.

Recibido: $19 / 11 / 2019$

Aprobado: 4/3/2020
} 


\section{Introducción}

El carcinoma de células de Merkel es un infrecuente tumor maligno primario de piel que fue descrito por Toker $^{(1)}$, en 1972.

Se estima una incidencia que oscila entre 0,1 a 1,6 casos por 100.000 habitantes por año ${ }^{(2)}$. En Estados Unidos la cifra reportada es de 1.600 casos anuales, siendo las regiones corporales más frecuentemente afectadas las expuestas al sol (cabeza, cuello y miembros) ${ }^{(3)}$.

Pocos casos han sido reportados en la literatura internacional de esta enfermedad en una zona no expuesta a las radiaciones ultravioletas, como es la región glútea ${ }^{(4-15)}$.

El objetivo de este trabajo es presentar un caso clínico de esta enfermedad topografiada en la región glútea.

\section{Caso clínico}

Paciente de 63 años, sexo masculino, de raza blanca, que consultó por tumoración de región glútea derecha de un año de evolución, de crecimiento rápido, color violáceo, límites netos, consistencia dura, de 2 por $2 \mathrm{~cm}$, que asienta sobre piel sana (figura 1). No se palparon adenomegalias inguino crurales.

Se realizó la resección completa de la lesión con anestesia local (figura 2).

El estudio histológico e inmunohistoquímico de la pieza diagnosticó un carcinoma de células de Mekel (figuras 3, 4 y 5).

Con dicho diagnóstico se realizó la evaluación de diseminación a distancia mediante tomografía computada tóraco abdómino-pélvica y tomografía por emisión de positrones (PET). No se evidenció enfermedad diseminada, por lo cual de acuerdo a la clasificación de TNM, correspondió al estadio I.

Posteriormente se completó el tratamiento con radioterapia adyuvante del lecho tumoral. Se realizó en series de 56 Gy durante 5,4 semanas, con buena tolerancia.

Actualmente, paciente asintomático y en control desde hace un año.

\section{Discusión}

El carcinoma de células de Merkel es un tumor altamente agresivo y constituye la segunda causa de muerte por cáncer primario de piel.

De etiopatogenia multifactorial, se destaca fundamentalmente: exposición a la luz solar, inmunodeficiencias como leucemia, linfoma, infección por HIV e inmunosupresión y un nuevo poliomavirus, el poliomavirus de células de Merkel (MCPyV), el cual se asocia a 80\% de los $\operatorname{casos}^{(2)}$. Dado que la radiación ultravioleta es el principal factor de riesgo y lo comparte con el carcinoma escamoso de piel, este último ha sido reportado como antecedente en $13 \%$ de los casos comunicados por Medina $\operatorname{Franco}^{(16)}$.

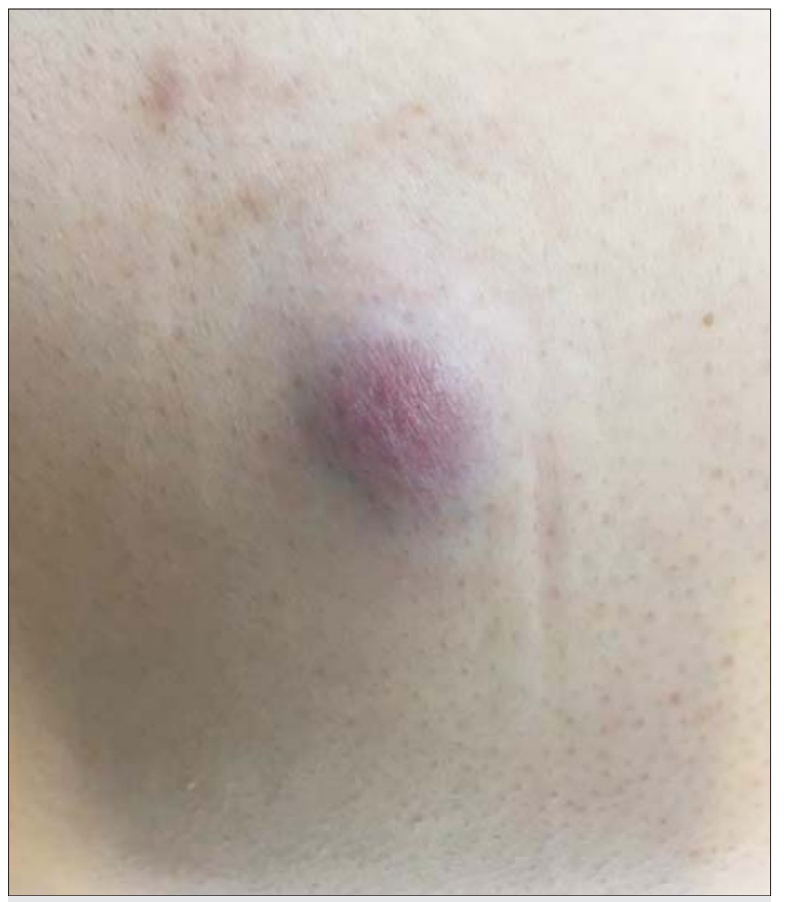

Figura 1. Lesión nodular de región glútea derecha.

La piel oscura parece ser un factor protector, ya que el 98\% de la casuística internacional ocurrió en población caucásica, como es el caso de nuestro paciente ${ }^{(16)}$.

Predomina en el sexo masculino en la séptima década de la vida, como ocurrió en este caso.

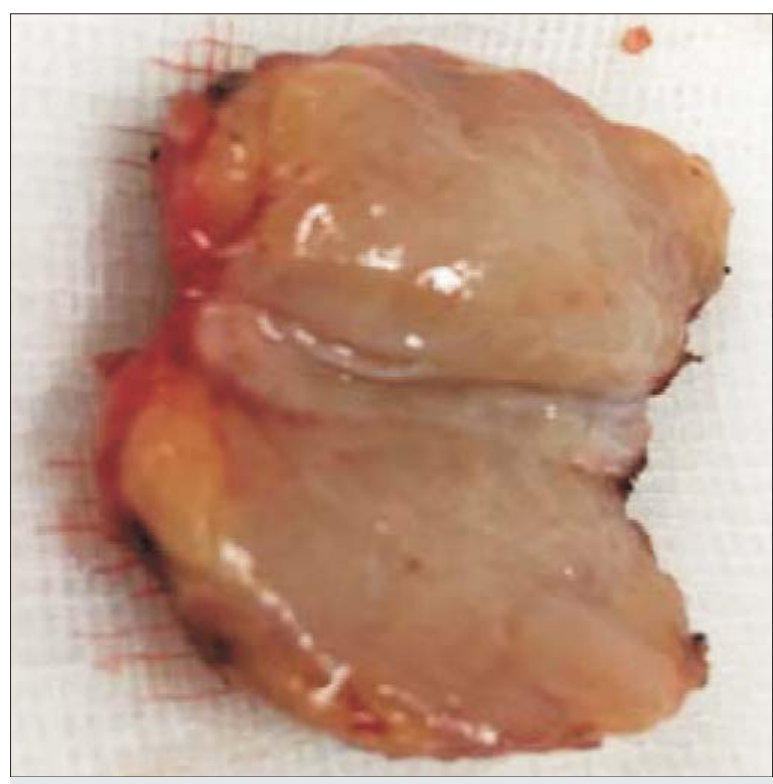

Figura 2. Pieza de resección quirúrgica abierta por su parte media. 


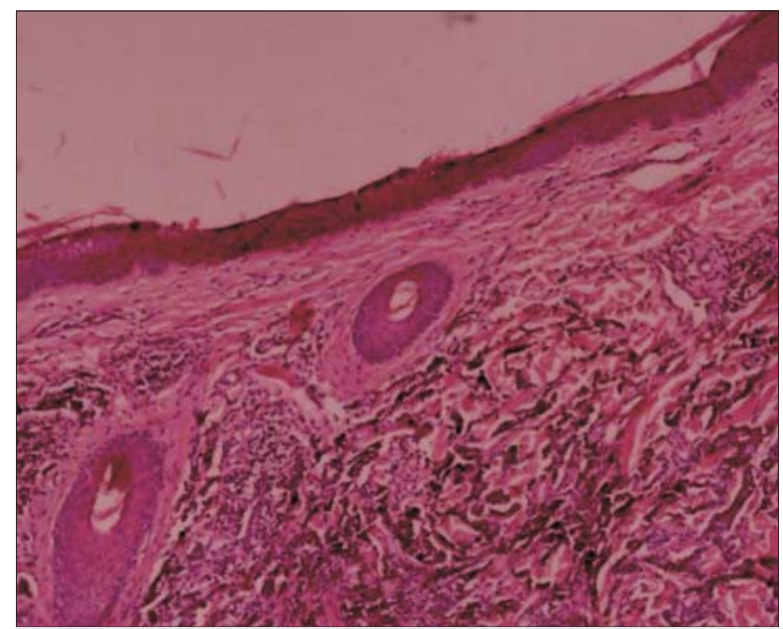

Figura 3. Microscopía que muestra lesión que respeta la dermis.

Se manifiesta como un tumor solitario, indoloro, ligeramente eritematoso o violáceo, brillante, cubierto de piel sana y de rápido crecimiento.

$\mathrm{La}$ afectación ganglionar se encuentra presente o aparecerá en la evolución hasta en el 55\% de los casos y la diseminación a distancia hasta en $31 \%{ }^{(16)}$.

El diagnóstico se puede realizar mediante biopsia por punción, incisional o escisional. Esta última conducta fue la adoptada en nuestro paciente.

$\mathrm{Su}$ confirmación es histológica y los marcadores de inmunohistoquímica CK 20, CK 7 y TTF 1 presentan una alta sensibilidad y especificidad.

La evaluación de la diseminación a distancia se realiza mediante tomografía computada con contraste, resonancia magnética y PET.

El tratamiento varía según el estadio y conlleva un abordaje multimodal que incluye cirugía local y regional, RT y QT. La inmunoterapia es la modalidad más innovadora.

Existen grupos de trabajo que proponen sustituir la QT como primera línea de tratamiento para EIV, por el uso del anticuerpo monoclonal avelumab, el cual está asociado con respuesta temprana y duradera y un buen perfil de seguridad, con una sobrevida libre de enfermedad de 9,1 meses promedio. JAVELIN Merkel 200 es el estudio prospectivo más amplio, el cual propone dicho cambio y se encuentra en fase B.

Actualmente, las guías NCCN recomiendan el uso de anticuerpos monoclonales, como pembrolizumab, para el tratamiento de la recurrencia local de enfermedad avanzada.

Se acepta que la resección con un margen de $2 \mathrm{a} 3 \mathrm{~cm}$ es suficiente ${ }^{(17)}$. En caso de compromiso ganglionar se recomienda el vaciamiento, y cuando clínica e imageno-

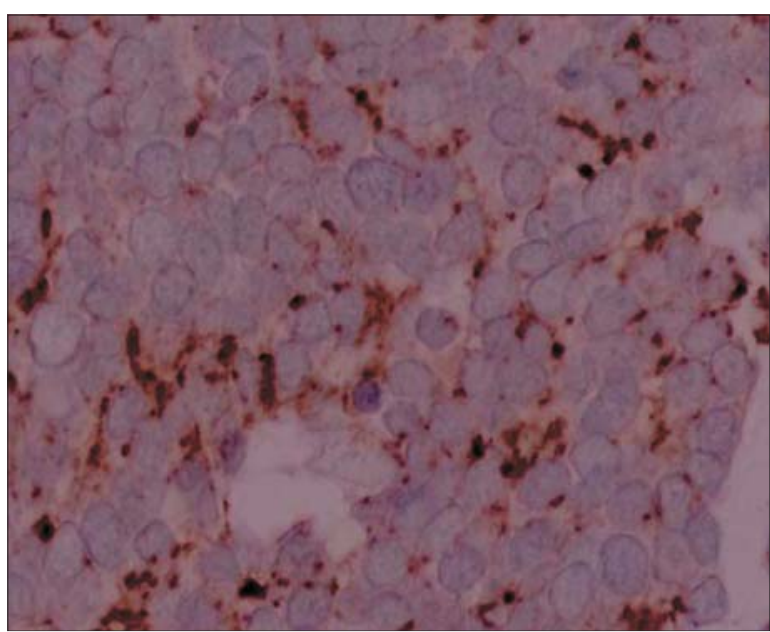

Figura 4. Marcación con IHQ positiva para CK20.

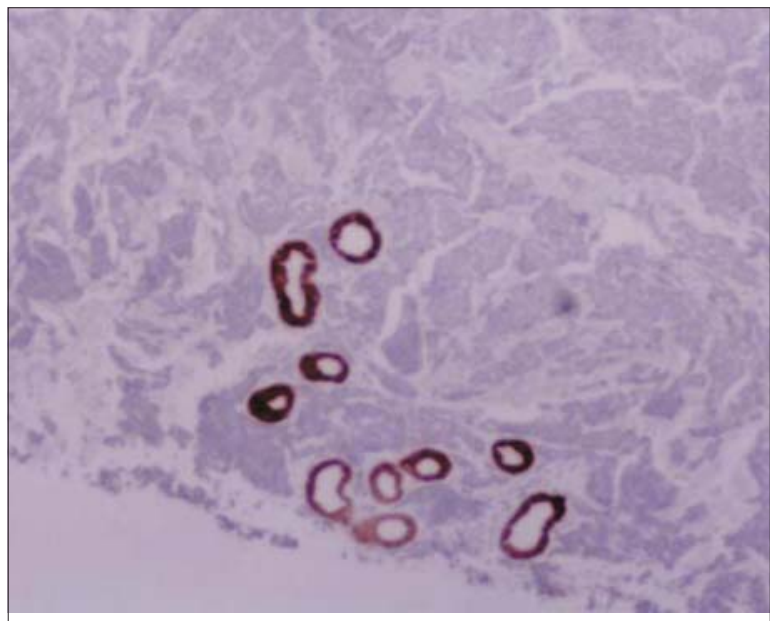

Figura 5. Marcación con IHQ positiva para cromogranina.

lógicamente no hay enfermedad ganglionar, se recomienda el estudio del ganglio centinela ${ }^{(2)}$. Con este procedimiento se ha demostrado hasta $29 \%$ de metástasis ocultas $^{(18)}$.

La recidiva tumoral asciende a $30 \%$ a los dos años de realizado el diagnóstico y la sobrevida a cinco años es de $51 \%, 35 \%$ y $14 \%$ cuando la enfermedad está limitada a la piel, tiene compromiso ganglionar o diseminación a distancia, respectivamente.

\section{Summary}

Introduction: Merkel cell carcinoma is a malign primary tumour that mainly affects regions that are exposed to solar radiation. Few cases have been reported in a region that is not exposed to the above mentioned risk factor, as the gluteal regions. 
The study aims to communicate the clinical case of a Merkel cell carcinoma of the gluteal region.

Clinical case: 63 -year-old male patient who consulted for a tumour with a $2 \mathrm{~cm}$ diameter in the right gluteal region, rapidly growing, being completely resected in a cordinaterd surgery under anesthesia. Pathology study revealed that it was Merkel cell carcinoma. No distance dissemination was seen, and thus as per the TNM staging system it was classified as stage I. Therapy was completed with local radiotherapy, It is currently under follow up and asymptomatic.

Discussion: Merkel cell carcinoma are highly aggressive tumours. Apart from solar radiation as a risk factor, it is worth mentioning immunodeficiency and a new polyomavirus, the Merkel cell polyomavirus.

This condition can be seen as purple, rapidly growing tumours and they frequently involve synchronic or metachronic lymph node compromise. Surgical resection with sufficient margins and lymph node emptying, in the event of lymph node compromise or sentinel node biopsy is recommended. Prognosis depends on the stage and a 30\% relapse has been reported after 2 years.

\section{Resumo}

Introdução: o carcinoma de células de Merkel é um tumor primário maligno de pele que afeta fundamentalmente regiões expostas às radiações solares. São poucos os casos relatados em uma região não exposta a esse fator de risco, como é a glútea.

O objetivo desta comunicação é apresentar o caso clínico de um carcinoma de células de Merkel de região glútea.

Caso clínico: paciente de 63 anos, sexo masculino que consultou por tumoração de $2 \mathrm{~cm}$ de diâmetro, na região glútea direita, com rápido crescimento que foi ressecada completamente em uma cirurgia eletiva com anestesia. O laudo anatomopatológico foi: carcinoma de células de Merkel.

Não se evidenciou disseminação a distância por isso foi classificado como estádio I de acordo com a classificação TNM. O tratamento foi completado com radioterapia local. Atualmente em seguimento e assintomático.

Discussão: os carcinomas de células de Merkel são tumores altamente agressivos. Além da radiação solar, a imunodeficiência e um novo poliomavirus, o poliomavirus de células de Merkel, são mencionados como fator de risco. Apresentam-se como tumorações de cor violácea e crescimento rápido e frequentemente se observa compromisso ganglionar sincrônico ou metacrônico. A ressecção cirúrgica com margens suficientes e esvaziamento ganglionar, quando há compromisso ou estudo de gânglio sentinela quando não há, é a conduta indicada. $\mathrm{O}$ prognóstico depende do estádio e há registros de até $30 \%$ de recidiva a 2 anos.

\section{Bibliografía}

1. Toker C. Trabecular carcinoma of the skin. Arch Dermatol 1972; 105(1):107-10.

2. Coggshall K, Tello TL, North JP, Yu SS. Merkel cell carcinoma: an update and review: pathogenesis, diagnosis, and staging. J Am Acad Dermatol 2018; 78(3):433-42.

3. Tello TL, Coggshall K, Yom SS, Yu SS. Merkel cell carcinoma: an update and review: current and future therapy. J Am Acad Dermatol 2018; 78(3):445-54.

4. Marcos Sánchez F, Albo Castaño MI, Viana Alonso A, Zapata Ingelmo A. Carcinoma de células de Merkel. An Med Interna 2005; 22(3):148-9.

5. Gonzailez Romero N, Peìrez Barrio $\mathrm{S}$, Cancho Galaìn $\mathrm{G}$, Blanch Rius L, Saìnchez Diez A, Izu Belloso R. Carcinoma de ceilulas de Merkel. Un caso clínico de presentacioìn atiìpica. Med Cutan Iber Lat Am 2018; 46(1):59-62.

6. Fernández-Regueiro R, Suárez-Sánchez FJ, Morís-de la-Tassa J. Merkel cell carcinoma. Report of a case with an atypical location and presentation. Rev Esp Cir Ortop Traumatol 2019; 63(4):313-5.

7. Turkkan G, Agdogan O, Saynak M, Uygun AC, Ustun F. Recurrent Merkel cell carcinoma of the gluteal region: a case report. Dermatol Ther 2019; 32(1):e12749.

8. Shanbhag S, Amonkar A. Merkel cell carcinoma. Indian J Surg Oncol 2018; 9(1):110-3.

9. Acab JC, Kvatum W, Ebo C. A 76 year old male with an unusual presentation of merkel cell carcinoma. Int J Surg Case Rep 2016; 23:177-81.

10. Kartal K, Hamaloglu E. Metastatic Merkel Cell Carcinoma (MCC) of pancreas. Chirurgia(Bucur) 2015; 110(3):287-90.

11. Krejcí $\mathbf{K}$, Tichý $\mathbf{T}$, Horák $\mathbf{P}$, Ciferská $\mathbf{H}$, Hajdúch $\mathbf{M}$, Srovnal J, et al. Merkel cell carcinoma of the gluteal region with ipsilateral metastasis into the pancreatic graft of a patient after combined kidney-pancreas transplantation. Onkologie 2010; 33(10):520-4.

12. Candrian C, Ruedi T, Furrer M. Merkel cell carcinoma. Retrospective analysis of 4 cases with special reference to diagnosis, therapy and long-term outcome. Swiss Surg 2002; $8(5): 215-9$.

13. Cecchetti E, Del Duca M, Bardella D, Geminiani L. Radiotherapy in the treatment of Merkel cell tumors. Radiol Med 1992; 84(1-2):123-31.

14. Turi V, D'Abrosca F, Lucev M, Gerosa E. A case of recurrent, metastatic Merkel's tumor localized in the gluteal region. Minerva Chir 1990; 45(3-4):199-201.

15. Suaìrez Pinbera $S$, Rodriìguez Arce $A$, Carvajal Ailvarez M. Carcinoma neuroendócrino cutáneo en un paciente anciano (poster). En: IV Congreso Nacional de Medicina General y de Familia. Donostia/San Sebastián: 2017. Disponible en: 
http://congresos-semg.es/sanse2017/dmdocuments/poster-merkel.pdf [Consulta: 14 enero 2019].

16. Medina-Franco H, Urist MM, Fiveash J, Heslin MJ, Bland KI, Beenken SW. Multimodality treatment of Merkel cell carcinoma: case series and literature review of 1024 cases. Ann Surg Oncol 2001; 8(3):204-8.

17. Savage P, Constenla D, Fisher C, Thomas JM, Gore ME. The natural history and management of Merkel cell carcino- ma of skin: a review of 22 patients treated at the Royal Marsden Hospital. Clin Oncol(R Coll Radiol) 1997; 9:164-7.

18. Fields RC, Busam KJ, Chou JF, Panageas KS, Pulitzer MP, Kraus DH et al. Recurrence and survival in patients undergoing sentinel lymph node biopsy for merkel cell carcinoma: analysis of 153 patients from a single institution. Ann Surg Oncol 2011; 18(9):2529-37.

\section{Contribución de autores:}

Ambos autores participaron por igual en las distintas etapas de elaboración del artículo.

Jimena Garmendia, https://orcid.org/ 0000-0002-3013-0776.

Daniel González González, https://orcid.org/0000.0003.3916.9201. 